Journal of Mathematics and Statistics 7 (3): 216-221, 2011

ISSN 1549-3644

(C) 2011 Science Publications

\title{
Optimizing Empty Containers Distribution among Ports
}

\author{
Mohammed A. Hajeeh and Weam Behbehani \\ Techno-Economics Division, \\ Kuwait Institute for Scientific Research, Kuwait
}

\begin{abstract}
Problem statement: Empty containers are an essential part of the logistics of the movement, repositioning and distribution of containers. Optimizing the allocation and transportation of empty containers contributes significantly in reducing cost. Approach: A mathematical model is formulated with the objective of finding an optimal sequence of ships movement among ports in order to satisfy demands at the ports with minimum total cost. Results: Several numerical examples are used to compare the performance of the developed optimization model with well known standard models available in the literature. Conclusion/Recommendation: It was observed that the solution obtained by the developed method to be either as good as or better than the solution provided by other standard models. Future work should consider contribution of full containers in meeting demand for empty containers.
\end{abstract}

Key words: Ships, optimal sequence, minimum cost, mathematical model, containers movement, capacitated plant location problem, time period, transportation problem

\section{INTRODUCTION}

Containers were introduced in maritime shipping in the 1960's of the last century as an important means of transporting goods. Containers had contributed significantly in making transportation easier and faster and in reducing encountered handling costs. However, it had brought about some problems such as preloading, owning or leasing and repositioning in addition to the problem of handling, acquisition and maintenance which are very costly. Today approximately $60 \%$ of maritime cargo is transported in containers. Literature related to maritime containerizing and optimization is extensive and detailed. Francesco et al. (2009) studied the maritime problem dealing with the non-deterministic nature of the historical data that deals with empty containers repositioning. The existence of uncertainty in the parameters makes it very difficult for the decision makers to take the proper actions. In order to overcome such problem, a time-extended multi-scenario optimization model was developed. The different scenarios were based on expert opinion obtained from the different shipping companies.

In their attempt to study resource allocation in shipping lines, Qingcheng et al. (2010) built a deterministic model based on equilibrium principle for shipping liners. The model expanded to an optimization model that takes into account the different uncertain parameters and factors. This robust model treats the ship size and slot allocation in the port as the design and the control variables, respectively. Hajeeh (2011) formulated two nonlinear mathematical models with the objective of finding the optimal failure and repair rates for a system that is deteriorating over time. The system was assumed to be imperfectly repaired after each failure. In the first model, the failed system was replaced by a new one after several imperfect repairs, while in the second model and upon each failure the system was either replaced or imperfectly repaired with different probabilities.

Lei and Church (2011) developed models for locating empty containers yards, the objective was to select a convenient location away from the ports such that the travel time involved in repositioning empty containers is minimized. The port complexes at Los Angeles and Long Beach were taken as an example in order to show that the savings associated with storing empty containers are usually overestimated when neglecting the trucking company's viewpoint. Chou et al. (2010) studied containers transportation problems using fuzzy logic approach. In this regards, a two stage fuzzy multiple criteria optimization model was developed with the objective of minimizing the transportation cost in addition to considering the volume of containers and port facility conditions. In the first stage, containers demand split rate was computed, while in the second case network optimization model was developed to determine the inland origin destination of import/export containers.

Corresponding Author: Mohammed A. Hajeeh, Techno-Economics Division, Kuwait Institute for Scientific Research, P.O. Box 24885; Safat-13109; Kuwait Tel: +965-2498-9500 Fax: +965-2498-9499 
Song and Dong (2011) used simulation and mathematical modeling to find an appropriate policy for the problem of repositioning empty containers in the presence of flexible destination ports. In this regards, no specific ports were chosen in advance, however, empty containers are unloaded in ports based on demand. Onut et al. (2011) examined a real life problem which was faced by a firm in Turkey. This firm deals with around thirty-party logistics companies and uses different ports each time. The objective was to select among many ports, the most convenient one. The selection process was based on several quantitative and qualitative factors that are complex and conflicting. Hence, the fuzzy analytic network process approach was utilized in order to overcome the vagueness associated with the problem. In this approach, six main criteria were used along with twenty sub-criteria. Fan et al. (2010) developed an optimization model for studying the transportation network of containers shipped to the United States of America. Sensitivity analysis was used for evaluating the impacts of congestion on capacity constraints and on the alternative routes in the shipment transport.

Bandeira et al. (2009) presented decision support systems integrating both full and empty containers. The problem was modeled as a network; a management approach was developed for the allocation and the distribution of the containers. Here, the distribution planning was integrated in a user friendly manner. Wong et al. (2009) developed a Hybrid Artificial Immune Systems (HAIS) algorithm for solving multiobjective optimization problems. This algorithm has been successfully applied to the problem of global repositioning containers. It was claimed that the developed HAIS will assist shipping liners too optimally and cost effectively reposition containers globally. Investigated the relationship between quay cranes, yard machines and container locations in a multi-berth and multi-ship environment. The main objective was to build a model for improving the operation efficiency of the seaports and to develop an analytical tool for yard operation planning.

\section{MATERIALS AND METHODS}

Containerization has become the most significant mode of operations nowadays. Containers come into different shapes and sizes and move between ports either as full carrying goods demanded in other ports, or as empty to be filled in another port. Although full containers have allocation priority, empty containers are on the move and are necessary for new shipments. Empty container are in high demand, their allocation problem is complex. They are either owned or leased and have to be optimally allocated in the different ports. There are many costs associated with containers; these include storage cost, repair cost, maintenance cost and inspection cost, transportation cost, handling cost, ship berthing cost and cleaning cost among others.

The main objective of this research work is to find the optimal movement of empty containers among ports to meet demand at minimum cost. There are many constraints that are considered in this problem, these are: Demand for shipments to be transported from one port to another at a given time, demand for empty containers to carry such shipments among ports at a given time period, demand for space on board of a ship that is journeying among ports in order to carry the demanded shipments (full containers) and empty containers, balance equations for empty containers in each port at any given time period, a balance equation for the space available in a ship after leaving a port in a given time period. Note that space in a ship is counted in terms of number of containers.

The assumptions are: All containers are of the same size and type, empty containers stored in a given port should not exceed its storage capacity, containers loaded on board of a ship should not exceed the ship's capacity at any time and number of ships berthed in a port in any time period should not exceed the maximum allowable number (port capacity). The problem is presented schematically in Fig. 1.

The general model for transporting empty containers by $\mathrm{s}$ ships to satisfy demands at $\mathrm{p}$ ports is presented by the following mathematical model (P1):

$\operatorname{minimize} \mathrm{Z}=\sum_{\mathrm{p}=1}^{\mathrm{P}} \sum_{\mathrm{s}=1}^{\mathrm{s}}\left(\mathrm{C}_{\mathrm{ps}} \mathrm{X}_{\mathrm{ps}}+\mathrm{K}_{\mathrm{ps}} \mathrm{Y}_{\mathrm{ps}}\right)$

Subject to:

$\sum_{s=1}^{\mathrm{s}} \mathrm{X}_{\mathrm{ps}}=\mathrm{a}_{\mathrm{p}}, \mathrm{p}=1,2, \ldots ., \mathrm{P}$

$\sum_{s=1}^{\mathrm{S}} \mathrm{X}_{\mathrm{ps}} \leq \mathrm{A}_{\mathrm{s}}, \mathrm{p}=1,2, \ldots ., \mathrm{P}$

$\mathrm{X}_{\mathrm{ps}} \leq \mathrm{a}_{\mathrm{p}} \mathrm{Y}_{\mathrm{ps}}, \mathrm{p}=1,2, \ldots ., \mathrm{P} ; \mathrm{s}=1,2, \ldots ., \mathrm{S}$

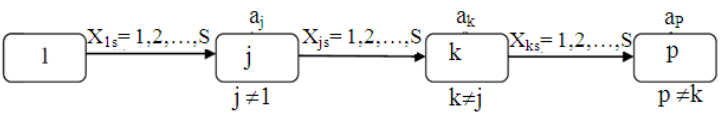

Fig. 1: A schematic presentation of the shipping problem 
$\mathrm{X}_{\mathrm{ps}}$ are positive integers, $\mathrm{p}=1,2, \ldots, \mathrm{p} ; \mathrm{s}=1,2, \ldots ., \mathrm{S}$

$\mathrm{Y}_{\mathrm{ps}}=0$ or $1, \mathrm{p}=1,2, \ldots ., \mathrm{P} ; \mathrm{s}=1,2, \ldots, \mathrm{S}$

Where:

$\mathrm{X}_{\mathrm{ps}}=$ Number of empty containers carried by ship $\mathrm{s}$ to meet demand at port $\mathrm{p}$.

$\mathrm{Y}_{\mathrm{ps}}=$ Number of stoppage made by ship $\mathrm{s}$ at port $\mathrm{p}$.

$\mathrm{C}_{\mathrm{ps}}=$ Cost of transporting an empty container by ship $\mathrm{s}$ to port $\mathrm{p}$.

$\mathrm{K}_{\mathrm{ps}}=$ Stoppage cost imposed on ship s at port $\mathrm{p}$.

$a_{p}=$ Number of empty containers demanded at port $p$.

$\mathrm{A}_{\mathrm{s}}=$ Space availability on board of ship $\mathrm{s}$, measured in number of empty containers.

The above problem (P1) cannot be easily solved analytically by existing techniques. However, when examined closely, the structure of the problem is found to possess some features of the well known Capacitated Plant Allocation Problem (CPL). The CPL problem could be simply stated as follows: Given there are $n$ potential plants locations and $m$ set of customers to be supplied from selected plants with the objective of satisfying customers demand from the different plants at minimum cost. The mathematical model for the CPL is presented in several forms in the literature. The most popular structure is as follows:

minimize $\mathrm{Z}=\sum_{\mathrm{i}=1}^{\mathrm{m}} \sum_{\mathrm{j}=1}^{\mathrm{n}}\left(\mathrm{C}_{\mathrm{ij}} \mathrm{X}_{\mathrm{ij}}\right)+\sum_{\mathrm{i}=1}^{\mathrm{m}} \mathrm{K}_{\mathrm{i}} \mathrm{Y}_{\mathrm{i}}$

Subject to:

$$
\begin{aligned}
& \sum_{j=1}^{n} X_{i j} \leq a_{i} Y_{i}, i=1,2, \ldots ., m \\
& \sum_{i=1}^{m} X_{i j}=b_{j}, j=1,2, \ldots ., n \\
& X_{i j} \geq 0, i=1,2, \ldots ., m ; j=1,2, \ldots ., n \\
& Y_{i j}=0 \text { or } 1, i=1,2, \ldots ., m ; j=1,2, \ldots ., n
\end{aligned}
$$

The input parameters are:

$\mathrm{K}_{\mathrm{i}}=$ Fixed cost associated with plant $\mathrm{i}$

$\mathrm{a}_{\mathrm{i}}=$ Maximal capacity (output) at plant $\mathrm{i}$

$\mathrm{C}_{\mathrm{ij}}=$ Cost of supplying one unit of the product from the ith plant to the jth customer

$b_{j}=$ Number of units demanded by customer $j$

$\mathrm{m}=$ Total number of customers

The decision variables are:
$Y_{i}=$ Whether a plant is open in location $\mathrm{i}\left(\mathrm{Y}_{\mathrm{i}}=1\right)$ or is closed at the same location ., $\left(\mathrm{Y}_{\mathrm{i}}=0\right)$

$X_{i j}=$ Number of products shipped from the plant in location $\mathrm{i}$ to customer $\mathrm{j}$

The apparent difference between the main problem P1 and CPL lies mainly in the decision variable Y. In order to show that the solution of the original problem (P1) is close to that of some standard models in the literature; the original problem P1 has been modified and it was proved that its solution is close to that of the standard models. In this regards, the original problem P1 solution was compared to that of the Transportation Problem and the Capacitated Plant Location problem as explained by the two approaches below.

Approach 1: Transportation Problem (TP): This approach is based on solving the transportation version of the general problem and adding the appropriate stoppage costs to the optimal solution. The main steps of this approach are follows:

- Transform the original problem (P1) into the well known Transportation problem (TP) by excluding the stoppage costs.

- Solve the new TP using existing techniques in the literature.

- Add the port stoppage costs to the costs value obtained by the TP model. follows:

The problem is mathematically presented as $\operatorname{minimize} \mathrm{Z}=\sum_{\mathrm{p}=1}^{\mathrm{P}} \sum_{\mathrm{s}=1}^{\mathrm{s}}\left(\mathrm{C}_{\mathrm{ps}} \mathrm{X}_{\mathrm{ps}}\right)$

Subject to:

$\sum_{\mathrm{s}=1}^{\mathrm{S}} \mathrm{X}_{\mathrm{ps}}=\mathrm{a}_{\mathrm{p}}, \mathrm{p}=1,2, \ldots, \mathrm{P}$

$\sum_{\mathrm{s}=1}^{\mathrm{S}} \mathrm{X}_{\mathrm{ps}} \leq \mathrm{A}_{\mathrm{s}}, \mathrm{p}=1,2, \ldots, \mathrm{P}$

$\mathrm{X}_{\mathrm{ps}}$ are positive integers, $\mathrm{p}=1,2, \ldots, \mathrm{P} ; \mathrm{s}=1,2, \ldots ., \mathrm{S}$

Solving the above problem gives the optimal assignment of ships to ports. The added stoppage cost is as follows:

$\mathrm{K}_{\mathrm{ps}}=0$ if $\mathrm{Y}_{\mathrm{ps}}=0$

$\mathrm{K}_{\mathrm{ps}}>0$ if $\mathrm{Y}_{\mathrm{ps}}>0$ 
Thus the optimal solution of the problem $\mathrm{P}\left(\mathrm{Z}^{*}\right)$ is as follows:

$$
\mathrm{Z} *(\mathrm{P})=\mathrm{Z} *(\mathrm{P} 1)+\sum_{\mathrm{p}=1}^{\mathrm{P}} \sum_{\mathrm{s}=1}^{\mathrm{s}} \mathrm{K}_{\mathrm{ps}} \mathrm{Y}_{\mathrm{ps}} \quad \text { for } \forall \mathrm{Y}_{\mathrm{ps}}>0
$$

However, this approach does not always produce the optimal solution to the general problem (P1).

\section{Approach 2: Capacitated Plant Location Problem} (CPL): In this approach, the problem is transformed into several one ship problems. Hence, a specific ship is chosen and ports are assigned to it optimally by solving the one ship problem. Next, another ship is selected and ports are assigned to it and so on until either the demand for empty at all ports are met, or all available ships have already been assigned. The detailed steps are as follows:

1. Take the one ship model of problem P1 and by selecting any ship s, the structure becomes similar to the CPL.

2. Find the optimal solution of the previous structure by the available CPL algorithm, or develop a new algorithm.

3. Remove those ports that their demand is completely met by the ship in the system.

4. In ports where the demand is partially satisfied; the demand is modified to be equal to original demand minus the allocated number of empty container by the assigned ship.

5. If all demands are met go to 7, otherwise continue.

6. Assign a non-assigned ship and go to 1. If all ships are already assigned, go to 7.

7. Find the optimal solution and stop.

The solution of the general model is the sum of the solutions of the one ship models. The mathematical model for the one ship is as follows:

$\operatorname{minimize} \mathrm{Z}=\sum_{\mathrm{p}=1}^{\mathrm{P}}\left(\mathrm{C}_{\mathrm{p}} \mathrm{X}_{\mathrm{p}}+\mathrm{K}_{\mathrm{p}} \mathrm{Y}_{\mathrm{p}}\right)$

Subject to:

$$
\begin{aligned}
& X_{p} \leq a_{p} Y_{p}, p=1,2, \ldots ., P \\
& \sum_{p=1}^{P} X_{p} \geq A
\end{aligned}
$$

$\mathrm{X}_{\mathrm{p}}$ are positiveintegers, $\mathrm{p}=1,2, \ldots, \mathrm{P}$
$\mathrm{Y}_{\mathrm{p}}=0$ or $1, \mathrm{p}=1,2, \ldots, \mathrm{P}$

The above problem is the capacitated plant location problem with one ship and several ports. It also could be looked at as an assignment problem. Solving the problem, the following optimal solutions are obtained:

$$
\mathrm{Z}^{*}, \mathrm{X}_{\mathrm{p}}^{*}, \mathrm{a}_{\mathrm{p}}^{*}
$$

$\mathrm{X}_{\mathrm{p}}^{*}$ Can take one of several categories:

- $\mathrm{X}_{\mathrm{p}}^{*}=1, \mathrm{a}_{\mathrm{p}}^{*}=\mathrm{a}_{\mathrm{p}}$ some $\mathrm{p}$

- $\mathrm{X}_{\mathrm{p}}^{*}=1, \mathrm{a}_{\mathrm{p}}^{*}<\mathrm{a}_{\mathrm{p}}$ some $\mathrm{p}$ different than port 1

- $\mathrm{X}_{\mathrm{p}}^{*}=0, \mathrm{a}_{\mathrm{p}}^{*}=0$ some $\mathrm{p}$ different than ports 1 and 2

It should be emphasized that any port in the system can be in one and only one of the above categories. Next a different ship is selected and a new mathematical model is formulated. This model has a similar structure as before, but with the following modifications:

- All ports with fully satisfied demand, i.e., as in the first category above are omitted from the first ship

- Ports where their demands are partially met by the first ship are included, but with modified demand, i.e., the new demand is equal to the original demand minus the demand met by the first ship

- Ports that are not supplied with any empty containers by the first ship. The new demand for these ports is the same as their original demand

Next, another non-assigned ship is selected with similar modification until either the demand for all ports are met or no ship is available in the system or both. Therefore the optimal solution of the complete problem is the sum of the solutions of the one ship problems. The following example is presented for illustration.

Examples: The following example is used to illustrate how the different models are used and to compare the results obtained from each.

Input data: Number of ships $(\mathrm{S})=3$, Number of ports $(\mathrm{P})=5$. In Table 1, the transportation costs encountered by moving one empty container by the various ships to the different ports are given. Other relevant parameters are also shown. In Table 2, the stoppage cost imposed by each port's authority on each ship is provided. 
Table 1: Transportation costs to the ports by the different ships Ports

\begin{tabular}{lllllll} 
Ships & 1 & 2 & 3 & 4 & 5 & Capacity \\
\hline 1 & 3 & 4 & 2 & 7 & 5 & 20 \\
2 & 7 & 2 & 3 & 6 & 8 & 12 \\
3 & 5 & 9 & 11 & 3 & 2 & 18 \\
Demand & 10 & 12 & 7 & 6 & 15 & 50 \\
\hline
\end{tabular}

Table 2: Ship stoppage cost at each port

\begin{tabular}{llllll}
\hline & Ports & & & & \\
& & & & & \\
& 1 & 2 & 3 & 4 & 5 \\
\hline Stoppage cost & 5 & 12 & 7 & 9 & 3 \\
\hline
\end{tabular}

\section{RESULTS}

Solving the problem using the above data in the different mathematical models is discussed below:

\section{The general model (P1):}

$$
\begin{aligned}
& X^{*}=164 \\
& X_{11}=10, X_{22}=12, X_{13}=7, X_{34}=6, X_{15}=3, X_{35}=12 \\
& Y_{1}=1, Y_{2}=1, Y_{3}=1, Y_{4}=1, Y_{5}=2
\end{aligned}
$$

\section{The transportation model:}

$$
\begin{aligned}
& X^{*}=125 \\
& X_{11}=10, X_{22}=12, X_{13}=7, X_{34}=6, X_{15}=3, X_{35}=12 \\
& Z=Z_{T}+Z_{j}^{*}=125+39=164
\end{aligned}
$$

\section{The Capacitated Plant Location (CPL) Model:}

\section{Sequence-1:}

Ship 1, Ship 2, Ship 3.

$$
\begin{aligned}
& Z^{*}=Z_{1}+Z_{2}+Z_{3}=74+36+54=164 \\
& X_{10}=10, X_{22}=12, X_{13}=7, X_{34}=6, X_{15}=3, X_{35}=3, X_{35}=12 \\
& Y_{1}=1, Y_{2}=1, Y_{3}=1, Y_{4}=1, Y_{5}=2
\end{aligned}
$$

\section{Sequence-2:}

Ship 3, Ship 1, Ship 2.

$$
\begin{aligned}
& Z^{*}=Z_{3}+Z_{1}+Z_{2}=51+57+80=188 \\
& X_{35}=15, X_{34}=3, X_{11}=10, X_{12}=3, X_{13}=7, X_{22}=9, X_{24}=3 \\
& Y_{1}=1, Y_{2}=2, Y_{3}=1, Y_{4}=2, Y_{5}=1
\end{aligned}
$$

\section{Sequence-3:}

Ship 3, Ship 2, Ship 1.

$$
\begin{aligned}
& Z^{*}=Z_{1}+Z_{2}+Z_{3}=74+63+54=191 \\
& X_{11}=10, X_{13}=7, X_{15}=3, X_{22}=12, X_{34}=6, X_{35}=12, X_{24}=3 \\
& Y_{1}=1, Y_{2}=1, Y_{3}=1, Y_{4}=2, Y_{5}=2
\end{aligned}
$$

\section{DISCUSSION}

It can be deduced from the results produced by the example that transforming the original problem into the well known transportation problem version is the best option. Such approach results in producing an optimal solution with minimum cost. While, using that of the capacitated plant location problem version requires solving several combinations of the problem in order to come up with the sequence that produces the optimal solution.

\section{CONCLUSION}

Strategically and optimally moving and storing containers is essential in the transportation establishments. Empty containers movement and distribution is an integral part of maritime business. In this research work, attempts were made to solve relaxed versions of the complex problem of empty containers shipment. Since solving the complete problem analytically is tedious and challenging, the strategy was to transform the original into well known structured standard methods in the literature and to develop new algorithms to solve the resulted problems.

Future work should address the movement of both empty and full containers, since full containers contribute to satisfying the demand for empty containers in subsequent ports upon unloading their goods. Another option is to introduce nonlinear cost functions associated with transporting empty containers among ports which are more realistic and thus solving a nonlinear mathematical programming problem.

\section{REFERENCES}

Bandeira, D.L., J.L. Becker and D. Borenstein. 2009. A DSS for integrated distribution of empty and full containers. Decision Support Syst., 47: 383-397. DOI: $10.1016 /$ j.dss.2009.04.003

Chou, C.-C., F.-T. Kuo, R.-H. Gou and C.-L. Tsai. 2010. Application of a combined fuzzy multiple criteria decision making and optimization programming model to the container transportation demand split. Applied Soft Comput., 10: 10801086. DOI: $10.1016 / \mathrm{j}$.asoc.2010.05.021 
Fan, L., W.W. Wilson and D. Tolliver. 2010. Optimal network flows for containerized imports to the United States. Transportation Res. Part E, 46: 735749. DOI: 10.1016/tre.2010.01.001

Francesco, M.D., T.G. Crainic and P. Zuddas. 2009. The effect of multi-scenario policies on empty container repositioning. Transportation Res. Part E, 45: 758-770. DOI: 10.1016/j.tre.2009.03.001

Hajeeh, M., 2011. Optimizing series repairable systems with imperfect repair. Int. J. Operat. Res. Inform. Syst., 2: 92-102. DOI: 10.4018/joris.2011040105

Lei, L.T. and R.L. Church, 2011. Locating short-term empty container storage facilities to support port operations: A user optimal approach. Transportation Res. Part E, 47: 738-754. DOI: 10.1016/j.tree.2011.01.004

Onut, S., U.R. Tuzkaya and E. Torun. 2011. Selecting container port via a fuzzy ANP-based approach: A case study in the Marmara Region, Turkey. Transport Policy, 18: 182-193. DOI: 10.1016/j.trapol.2010.08.001
Qingcheng, Z., Y. Zhongzhen and C. Chao, 2010. Robust Optimization model for resource allocation of container shipping lines. Tsinghua Sci. Technol., 15: 586-594. DOI: 10.1016/S1007-0214(10)70105$\mathrm{X}$

Song, D.-P. and J.-X. Dong, 2011. Effectiveness of an empty container repositioning policy with flexible destination ports. Transport Policy, 18: 92-101. DOI: 10.1016/j.tranpol.2010.06.004

Wong, E.Y.C., S.C. Henry and H.Y.K. Lau, 2009. Immunity-based hybrid evolutionary algorithm for multi-objective optimization in global container repositioning. Eng. Appli. Artif. Intell., 22: 842854 DOI: 10.1016/j.engappai.2008.10.010 